\title{
Research on the Development Path of Rural Electronic Commerce in the Perspective of Precision Poverty Alleviation
}

\author{
Wu Weidong \\ School of Public Administration, Yan'an University \\ Yan'an, China \\ 576223209@qq.com
}

\begin{abstract}
In order to make more and more benefits of the Internet to farmers, and achieve the new strategy of precision poverty as soon as possible, authors in this paper aim at the current problems in the development of rural electricity suppliers, under the guidance of "the sweet idea", take advantage of Taobao platform, put forward the corresponding countermeasures and suggestions on the logistics, finance and other aspects of the rural electricity suppliers. So that this new blue ocean of the rural electricity suppliers leads farmers to get rich, becomes a new engine to build a well-off society in an allround way.
\end{abstract}

Keywords-electronic business; e-shopping in rural areas; measures of poverty alleviation

\section{INTRODUCTION}

With the rise of the Internet as a national strategy, ecommerce make a new condition and create a higher starting point for achieving precision poverty strategy. The general office of the State Council recently issued Guiding Opinions on Accelerating the Development of Electronic Commerce in Rural Areas. It pointed out that by 2020, China will tentatively complete the construction of a rural e-commerce market system which is unified and open, competitive and orderly, honest and law-abiding, safe and reliable, green and environmental protecting. ${ }^{[1]}$

In the CNKI, there are 11736 articles from 2005 to 2015. Accurate analysis of the data in the last five years is made as followings:(1) the relevant scholars pay more and more attention in recent years, the number of literature is also growing. The number of literature on this topic suddenly rose in 2015.(2) There were 1293 effective articles. Among them, the research on the characteristics of regional about rural e-commerce, a total of 436 articles accounted for only $33.8 \%$ of the total literature. It's obvious that local ecommerce research should be carried out to explore the advantages and disadvantages of the development model in different regions, so as to provide the necessary theoretical basis for the development of rural e-commerce.

\author{
Xie $Y u$ \\ School of Public Administration, Yan' an University \\ Yan' an, China \\ 506313191@qq.com
}

\section{THE SIGNIFICANCE OF THE DEVELOPMENT OF RURAL ELECTRICITY SUPPLIERS}

A. From Ignorance to Transcendence-Improving Farmers' Consumption and Life

- Off-line-Taobao has changed the previous consumer habits of farmers, to create more convenience for farmers to shop.

- On-line- E-commerce has broken the limits of time and space, broaden the sales channels of agricultural products, reduce the degree of asymmetry of transaction information. It can bring considerable income for farmers.

B. Springhead-Improving Agricultural Products, Promoting Agricultural Modernization

- Reducing the risk of agricultural production. Rural e-commerce from the network to the cloud promotes the sale of agricultural products, reduces the risk of agricultural production.

- Reducing transaction costs of agricultural products. E-commerce builds a network platform for the sale of agricultural products. Electronic sales model achieves the national poverty from the "blood transfusion" to the "blood" of the transformation, it is conducive to promote the modernization of agriculture.

-C. Change Rapidly-Boosting the Development of New Urbanization in Rural Areas

The rise of rural e-commerce create a new model for the development of new urbanization, it is conducive to breakthrough the regional limits in rural areas, promote the talent of the reverse flow, effectively promote the new development of urbanization.

\section{CURRENT PROBLEMS IN RURAL ELECTRICITY SUPPLIERS}

According to statistics, from 2010 the average annual growth rate of agricultural sales of agricultural products was 
$112.15 \%$. Sales of agricultural products from about 3 billion 700 million RMB in 2010, to break through 80 billion RMB in 2014. ${ }^{[2]}$ However, e-commerce applications are still in the primary stage of development, there are many problems need to be solved.

\section{A. The Rate of Website Construction Repetition is High}

By the end of 2013, electricity suppliers trading website about all kinds of agricultural products are more than 3000 . Agricultural electricity suppliers in 2014 are still growing, close to 4000. [3] The website increases year by year, reflecting the increasing popularity of electronic commerce in China. This phenomenon also has a prominent problem, that is, the high rate of duplication of the site construction, the convergence of investment, the serious phenomenon of the homogenization, which led to confusion in the competition order, the loss of agricultural products sales.

\section{B. Logistics and Distribution Has Many Difficulties}

How to get through the "last mile" of the rural logistics is the first problem to be solved in the development of electronic commerce in the country. National Bureau of statistics data show that in September 2014, up to $60 \%$ of the rural residents think express delivery is not convenient. Except from Chinese post, major enterprises express outlets such as SF, "one of four" etc. can only reach to countryside. ${ }^{[4]}$

\section{The Standards of Product are Uneven}

At the present stage Chinese agriculture hasn't finished comprehensive modernization. Agricultural products of China are mostly produced by the scattered small peasant household, coupled with the agricultural production that will be interfered by natural factors. The standardization of agricultural products is very low. This can not guarantee the safety of agricultural products and brand effect.

\section{COUNTERMEASURES AND SUGGESTIONS TO PROMOTE RURAL ELECTRICITY SUPPLIERS}

The general office of the State Council accelerate the development of the guide by promoting the development of e-commerce in rural areas. The development of e-commerce in rural areas should strengthen policy support ; vigorously develop rural electricity suppliers talent; accelerate the improvement of rural logistics system; strengthen the construction of rural infrastructure; create a standardized and orderly market environment.$^{[5]}$ In view of the problems existing in the rural electricity supplier, to fit Alibaba strategic, under the guidance of the sweet idea, countermeasures about a platform, two pillars and the three major elements are proposed, hoping to further enhance the level of development of China's rural electronic business.

\section{A. The sweet idea:,,$+- \times, \div$}

"Sweet" is high-quality agricultural production platform in rural Taobao, committed to the unique integration of rural Taobao, local governments and village partner resources, seeking quality from the source of origin, traceability of agricultural products quality, presenting to the consumer. Sweet idea can be simply described as a formula add, subtract, multiply and divide.

- "+": For all the special advantages of agricultural products, increase of county and township government endorsement and Village people 's inspection product control link recommendation, supplemented by tracing to the source and the insurance guarantee mechanism, for your strict selection.

- ". " ": To reduce the time cost of agricultural production end arrived at the consumer side, space cost and sale cost, from farms to the table, fresh and rich, mail direct.

- “ $\times$ ": Agricultural products online will effectively move the local supply chain infrastructure, personnel training and brand development, overall, systematic drive to promote economic and social benefits.

- " $\div$ " : Remove of toxic and harmful additives in the process of agricultural products' manufacture, storage and transportation, remove of the numerous and complicated to distinguish between true and false rumors, return to the authentic food and allow the industry to restore trust.

\section{- B. A platform: Chinese library of Taobao featured}

The project started in 2010. Taobao tries their best to build the regional characteristics of high-quality goods shopping platform, a collection of tripartite efforts about Taobao. Local farmers and the local government, strengthen quality supervision and management. The main mission is local characteristics of food and crafts, to provide consumers with the most authentic local characteristics, food, crafts.

\section{- C . Two pillars :Rookie Logistics + Ant financial}

- Rookie Logistics. It is suitable to build China's vast rural areas of the platform type service network, boost the county economy transformation and development. Its advantage lies in: aging stable distribution service, safe and controlled storage and distribution services, diversified value-added services.

- Ant financial. At present, ant financial has covered 18 provinces, 107 cities. It is based on the public service window, to the people's livelihood big data as the core, aggregates traffic, social security, education and other industry applications. With innovation in the entity public service, throughout the entire process of public service, it creates real one-stop, all-weather service hall. 


\section{Three elements: people $\times$ goods $\times$ field}

Development of e-commerce in rural areas to help farmers get rid of poverty, it is important to achieve agricultural products online. Real sales $=$ people $\times$ goods $\times$ field.

- people: Who produces? Who sell? Today, the Internet consumers in the purchase of products, is more willing to believe that scene. Scene is the environment, as well as who is in the production of this product. we need to use the original and simple method, send the producer of information to consumers. The next needs to know who to sell these products. We should strengthen the construction of rural hardware facilities, to achieve universal promotion and sales, so as to achieve a virtuous circle of universal profit.

- Goods: What goods? Where to go? At present, the agricultural products in our country can only be called products, and the transformation from product to commodity is a standardized process. The need of agricultural products is a comprehensive standardized, it includes planting standards, procurement standards, packaging standards and so on. These standards are connected, it has formed a product to the commodity standardization system. Product characteristics determine the scope of sales. The first thing we should do is to make a layer of the product, as shown in Figure 1. ${ }^{[6]}$ Some products are suitable for regional circulation. Some can be sold to the national region. According to the regional level that the product is suitable for sale, and then we package products, plan product and so on.
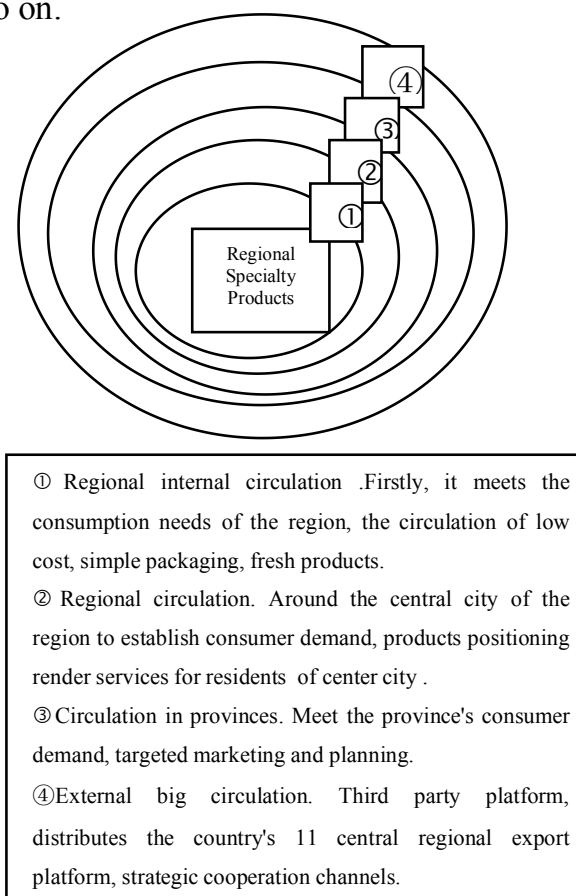

Figure1 The Range of regional specialty products' sale
Field:Where do you get together? Where do you sell it? Village service station as a transfer station, is the best choice for gathering agricultural products. The main service projects of village level service station are: sell online, buy online, entrepreneurship cultivation and the local life, accept and deliver of express items, book accommodation and so on. We have had people and goods, we should begin to find sales field. County public service system should be able to build relationships with the current sales of all platforms. Only Products have a relationship with more people, it is able to bring more sales.

\section{CONCLUSION}

Rural e-commerce is an important means to change the mode of agricultural development, is an effective carrier to achieve accurate poverty alleviation. Active participation of the electricity business giants, will push the new stage of rural electronic commerce. At the same time, the country try its efforts to create a good environment for agricultural products business. China's e-commerce laws and regulations, the standard system will continue to improve. The country will be the next new blue ocean of e-commerce development, this piece of blue ocean is full of profit emerging markets, but also is China's innovative business strategy to achieve accurate poverty alleviation. With the development of this piece of blue ocean , e-commerce will enable more agricultural products on the line, to create more wealth for the countryside, so that farmers get rid of poverty as early as possible to enjoy the new results of the reform and opening up.

\section{References}

${ }^{[1]}$ Zhao Jing. 《Opinions on accelerating the development of electronic commerce in rural areas 》 introduce 10 initiatives of the Ministry of Commerce[J]. Farmers Digest,2015,9,pp.9. (In Chinese)

[2] Hong Tao,Zhang Chuanling.Report on the development of electronic commerce of agricultural products in China from2014 to 2015 [J].Electronic Commerce, 2015,2,pp.44-54. (In Chinese)

[3] Hong aTo,Zhang Chuanling.Report on the development of electronic commerce of agricultural products in China from 2014 to 2015 [J].Electronic Commerce, 2015,2,pp.44-54. (In Chinese)

${ }^{[4]}$ Dong Peng,Ni Yue,Ji Wei. The road Electricity suppliers into rural areas must go[J].Food Safety,2015,11,pp.66-67.(In Chinese)

[5] State Office No. $\{2015\} 78$. Guiding opinions of the general office of the State Council on promoting the development of electronic commerce in rural areas [J].Bulletin of the state council, 2015 (32) .pp.118-120. (In Chinese)

${ }^{[6]}$ Worry about sales of agricultural products, Xi greatly point like this company but a year to sell 1 billion 500 million! [EB/OL].http://i.wshang.com/Post/Default /Index/pid/41974.html. (In Chinese) 